\title{
Pengaruh Role Model dan Religiusitas Terhadap Perilaku Antikorupsi pada Mahasiswa Organisatoris di Jawa Timur
}

\author{
Sakinah Nur Rokhmah \\ sakinah.snr@gmail.com
}

Julia Tirta Putri

Akbar Prasetyo Utomo

Fakultas Psikologi, Universitas Muhammadiyah Malang

\begin{abstract}
Abstrak
Indonesia is ranked in 117 out of 175 from the most corrupt countries in the world. The corruption phenomenon can be analyzed from the individual micro elements. In a person's life, there are people considered as a role model / anti-corruption figures. Considering that one could not control his desire, he tends to justify any way for his pleasure. It might be said that self-control is closely related to religiosity. In fact, corruption not only happens in official governors, but also in university students. It is ironic when we compare it with the ideal expectations of the community toward students as the future generation. The purpose of this research is to know the influence of role models and religiosity toward anti-corruption behavior. Quota Sampling is used to collect the data ( 440 students from nine universities in East Java) and moderated regression analysis (MRA) is utilised to analyze them. The result shows that the religiosity variable can not moderate independence and dependence variables. Nevertheless, role models have a significant effect to predict anti-corruption behavior by $12.7 \%$. Of four role model figures, teacher/lecturer figure has the largest contribution by $12,7 \%$ toward anti-corruption behavior. Unfortunately, this figure is considered having low anti-corruption behaviour by their student. The result of this research would be recommendation for the government to find the right agent to prevent and intervene corruption behavior and for the students to choose the right figure in fostering anti-corruption behaviour.
\end{abstract}

Keywords : Role model; Religiosity; Anti-corruption Behaviour

Psikoislamika : Jurnal Psikologi dan Psikologi Islam (JPPI) Volume 15. Nomor 2, Tahun 2018. copyright () 2018. Pusat Penelitian dan Layanan Psikologi.

Degradasi moral semakin marak diperbincangkan bangsa ini. Degradasi moral berkaitan dengan karakter bangsa yang menjadi sumber dari berbagai permasalahan yang ada di Indonesia. Rubiyantoro (2014) menjelaskan persoalan karakter bangsa akhir-akhir ini kian menjadi sorotan tajam masyarakat. Dari berbagai kasus yang ada, korupsi adalah yan paling merugikan.

Tabel 1. Peningkatan Jumlah Kasus Korupsi

\begin{tabular}{cc} 
Tahun & Jumlah Kasus \\
2012 & 402 \\
2013 & 560 \\
2014 & 629 \\
TOTAL & 1.271 \\
\hline
\end{tabular}

Berdasarkan survey Transparency International, pada 2011 hingga 2015, indeks persepsi korupsi (IPK) Indonesia masih mencapai angka 3, yang artinya Indonesia menempati peringkat ke 100 dunia dari 183 negara, dan hasil survei terakhir pada 2015 ini Indonesia menempati urutan ke 117 dari 175 negara terkorup di dunia (Kompas, 11 Desember 2015). Berdasarkan penelitian ahli, beberapa dampak yang merugikan dari korupsi adalah menurunnya pertumbuhan ekonomi dan investasi, dan berkurangnya alokasi dari belanja publik untuk pendidikan dan kesehatan, serta efisiensi alokasi sumber daya (Gathy, Paternostro \& Rogolini, 2003).

Namun, fakta yang berbeda terbukti dari hasil survey indeks perilaku antikorupsi tahun 2012- 
2014 yang dilakukan Badan Pusat Statistik (dalam Budiharto, 2015), dapat dilihat di tabel berikut:

Tabel 2. Indeks Perilaku Anti Korupsi (IPAK) Indonesia 2012-2014

\begin{tabular}{lll}
\hline Tahun & Indeks & Kategori \\
\hline 2012 & 3.55 & Anti Korupsi \\
2013 & 3.63 & Anti Korupsi \\
2014 & 3.61 & Anti Korupsi
\end{tabular}

Keterangan : Nilai Indeks bergerak dari 0-5

$0-1.25$ : Sangat permisif terhadap korupsi

1.26 - 2.50: permisif;

$2.51-3.75$ : anti korupsi;

$3.76-5.00$ : sangat anti korupsi

Hasil survey tersebut dapat dimaknai, bahwa masyarakat Indonesia memiliki potensi yang baik untuk bangkit dari keterpurukan korupsi. Namun, hal ini menjadi pertanyaan besar mengapa hingga saat ini kasus korupsi di Indonesia masih saja tinggi. Secara psikologis, korupsi menyebabkan rendahnya rasa saling percaya (trust) antar orang dan kurangnya perghargaan pada norma-norma hukum yang berlaku. Penelitian Dayakisni (2015) pada remaja di Balikpapan, membuktikan bahwa sinisme sosial berhubungan positif dengan perilaku korupsi pada remaja. Sinisme sosial erat kaitannya dengan fenomena kurangnya penghargaan pada norma hukum yang telah ada.

Korupsi tentunya dapat terjadi karena adanya niat dari sang pelaku. Dalam ilmu psikologi, kita mengenal niat sebagai intensi. Salah satu faktor intensi seseorang adalah pengalaman yang telah dilewatinya. Dalam kehidupan seseorang pastinya terdapat interaksi dengan orang lain di sekitarnya, yang membuat individu menganggap orang lain sebagai figur/role model. Role model bisa jadi berasal dari lingkungan terdekatnya, atau orang yang dianggap memiliki kesamaannya dengannya. Pengalaman inilah yang dapat mempengaruhi intensi seseorang untuk melakukan suatu perilaku. Termasuk pada kasus korupsi, pengalaman yang telah dilewati seseorang dapat memunculkan intensinya dalam berkorupsi. Terutama pengalaman yang berkaitan dengan orang yang dianggap sebagai role model. Perilaku role model yang akhirnya diresapi oleh individu adalah ketika yang dilakukan oleh role model menciptakan harapan jika hal serupa dilakukan oleh sang pengamat tersebut (Bandura, 1986). Ketika melihat orang lain berperilaku korupsi dan menganggap korupsi dapat memberikan kesenangan secara instan tanpa kerja keras yang berlebihan, hal tersebut membuat individu cenderung ingin melakukannya juga. Terutama jika kita melihat kurangnya penegakan hukum terhadap koruptor yang terbukti korupsi.

Menurut Hidayat (2013), salah satu sifat bawaan manusia itu selalu mendekati dan mengejar kesenangan (pleasure) dan menghindari penderitaan (pain). Dalam konteks korupsi, mengingat korupsi cepat mendapatkan kekayaan tanpa mesti kerja keras, secara psikologis seseorang akan mudah tergerak untuk korupsi. Jika seorang individu tidak dapat mengontrol hasrat tersebut, maka akan memiliki kecenderungan untuk menghalalkan segala cara agar mendapatkan kesenangan tersebut. Kontrol diri yang ada pada individu erat kaitannya dengan religiusitas. Religiusitas memberikan kerangka moral, sehingga membuat seseorang mampu membandingkan tingkah lakunya (Desmita, 2005). Kontrol diri yang rendah, salah satunya disebabkan karena religiusitas yang rendah. Terkait hubungan religiusitas dan intensi antikorupsi pernah dilakukan penelitian sebelumnya oleh Wahyuni dkk (2015), hasil penelitiannya membuktikan bahwa terdapat hubungan yang positif antara orientasi religius dengan intensi antikorupsi. Seharusnya Indonesia dengan jumlah mayoritas penduduknya beragama memiliki jumlah kasus korupsi yang rendah. Namun, pada kondisi kenyataannya masih belum seperti itu.

Jumlah kasus korupsi di Indonesia banyak melibatkan orang-orang terkemuka baik itu tokoh masyarakat maupun pemerintahan yang ada di birokrasi. Pejabat pemerintah sebagai model dan panutan, segala perilakunya akan dijadikan contoh oleh masyarakat. Sehingga, role model dapat berdampak pada perilaku masyarakat. Menurut Gacther dan Ranner (2014), politisi, pejabat pemerintah, dan manajer dapat berfungsi sebagai role model yang dianggap tepat dan dapat membentuk kepercayaan pengikutnya tentang suatu perilaku. Wakhidah (2014), juga menjelaskan bahwa korupsi juga dapat terjadi karena dukungan sosial. Baik oleh orang tua maupun pihak keluarga yang bermental materialis, hingga membuat 
seseorang mengambil keputusan untuk melakukan tindak korupsi. Role model juga dapat muncul dari lingkungan kerja maupun teman. Penelitian Aultman (1976) membuktikan bahwa korupsi di kepolisian dapat timbul karena proses interaksi antar individu polisi yang melibatkan penyalahgunaan kewenangan peran kerja petugas polisi.

Pada kenyataanya, kasus korupsi tidak hanya terjadi di lingkungan politik dan pemerintahan saja, namun juga pada mahasiswa. Menurut Walida (2015), beberapa perilaku korupsi yang muncul pada mahasiswa diantaranya korupsi waktu, mahasiswa tidak berangkat ke kampus, lebih memilih untuk membolos, tidak mengerjakan tugas dan pulang lebih cepat/awal sebelum waktunya. Selain itu, beberapa mahasiswa yang terlibat dalam kegiatan keorganisasian di kampus juga sering melakukan kebiasaan perilaku korupsi, misalnya saja merancang pendanaan kegiatan yang besar, lalu menyalahgunakan dana sisa untuk kepentingannya sendiri. Perilaku lainnya dalam bidang akademik, misalnya mencontek saat ujian dan menjiplak atau melakukan plagiasi karya milik orang lain dan mengakui sebagai miliknya. Sungguh ironi, jika kita sandingkan dengan harapan ideal masyarakat kepada mahasiswa. Mahasiswa adalah generasi penerus bangsa, tanggungjawab Indonesia nantinya akan dipegang oleh mahasiswa saat ini.

Selain itu, banyak pula organisasi dan komunitas gerakan antikorupsi yang telah digencarkan oleh mahasiswa, namun justru pada mahasiswa sendiri banyak perilaku korupsi yang muncul, dan jika kebiasaan tersebut terus berlangsung, maka dapat dipastikan mahasiswa saat ini dapat menjadi calon koruptor di masa depan nantinya. Penelitian Falah (2012) menunjukkan bahwa mahasiswa menilai perilaku korupsi yang dilakukan oleh pihak-pihak yang tidak memiliki keterlibatan dengan dirinya sebagai hal yang negatif, tetapi bila ada perilaku korupsi yang memiliki keterlibatan dengan dirinya akan cenderung lebih ditoleransi. Mahasiswa memang tidak secara nyata melakukan tindakan korupsi terhadap uang negara seperti layaknya pejabat pemerintah, namun mereka melakukan pelanggaran terhadap hal yang diamanahkan pada mereka.
Berdasarkan uraian tersebut maka rumusan masalah dalam penelitian adalah bagaimanakah pengaruh role model dan tingkat religiusitas dengan perilaku antikorupsi pada mahasiswa organisatoris di Jawa Timur. Tujuan dari penelitian ini adalah untuk mengetahui pengaruh role model dan tingkat religiusitas dengan perilaku antikorupsi. Urgensi dari penelitian ini, karena saat ini Indonesia sedang mengalami darurat korupsi, dibutuhkan penerus yang nantinya dapat membangkitkan dan membenahi bangsa Indonesia di masa depan, dan mahasiswa adalah salah satu penerus nyata perjuangan bangsa Indonesia.

Antikorupsi terbentuk oleh beberapa aspek (Wahyuni, 2015), yaitu: (1) Anti-bribe (antipenyuapan), (2) Anti-gratification (antigratifikasi),(3) Anti-fraud (antipenipuan)〉, (4) Anti-mark up (Antipenggelembungan dana),(5) Anti-black mail (Antipemalsuan) dan (6) Antinepotism (Antinepotisme). Sedangkan, antikorupsi merupakan kebalikan dari korupsi. Sehingga dapat disimpulkan bahwa, antikorupsi adalah bentuk menghindari perilaku jahat, busuk, dan merusak yang berkaitan dengan penyelewengan kekuasaan.

Model dalam dalam kamus psikologi (Reber\&Reber, 2010) diartikan sebagai sebuah representasi yang mencerminkan, menduplikasikan, mengimitasikan, atau sejumlah cara mengilustrasikan suatu pola hubungan yang bisa diamati di data atau alam. Sebuah gambaran ideal, sebuah standar, sebuah contoh yang dibentuk sebagai imitasi atau salinan yang berharga. Role model memainkan peranan penting karena sebagian besar sosialisasi diasumsikan berlangsung lewat pengimitasian perilaku model panutan. Role model adalah bagian dari teori modelling Bandura (1986). Tahapan observational learning(Modelling) yaitu, (1) Atensi/perhatian, (2) Retensi/ingatan (3) Produksi perilaku, dan (4) Motivasi/dorongan (Boeree, 2010, Feist\&Feist, 2010).

Hill dkk menjelaskan religiusitas berasal dari bahasa Latin yaitu "religio" yang menghubungkan antara manusia dan sesuatu yang lebih agung atau Tuhan. Pargament menawarkan definisi religiusitas sebagai mencari makna dalam cara-cara yang sakral atau suci (Raiya, 2008). Religiusitas memiliki lima aspek yaitu keyakinan, perbuatan, ethical - conduct do's, ethical - conduct don't dan kebersaman dalam Islam. 
Hipotesa dari penelitian ini adalah ada pengaruh yang positif antara role model dengan antikorupsi, semakin tinggi modelling pada tokoh yang berperilaku antikorupsi maka diikuti tingginya perilaku antikorupsinya. Pengaruh tersebut akan dipertimbangkan dengan tingkat religiusitas yang tinggi atau rendah pada diri individu tersebut.

Penelitian ini merupakan penelitian kuantitatif korelasional, yaitu bertujuan untuk mengetahui pengaruh variabel role model terhadap variabel perilaku antikorupsi yang nantinya akan dimediatori oleh variabel religiusitas. Penelitian ini dilaksanakan pada saat bulan Maret hingga bulan Juni, tahun 2017. Bertempat di perguruan tinggi yang digunakan sebagai sample diantaranya, Universitas Muhammadiyah Malang, Universitas Brawijaya, Universitas Islam Negeri Malik Ibrahim, Universitas Negeri Malang, Universitas Airlangga, Institut Teknologi Sepuluh November, Universitas Negeri Surabaya, Universitas Islam Negeri Sunan Ampel, dan Universitas Negeri Jember.

Subjek penelitian adalah mahasiswa S1 yang beragama islam, berstatus aktif dan memiliki rentang usia 18-24 tahun yang terdapat di perguruan tinggi negeri maupun perguruan tinggi swasta di Malang, mahasiswa tersebut telah/sedang mengikuti kegiatan organisasi kampus, kurang lebih selama satu tahun. Penelitian ini fokus kepada mahasiswa organisatoris yang beragama islam, karena di Indonesia islam merupakan agama mayoritas. Teknik sampling dalam penelitian ini dilakukan dengan cara Quota Sampling yaitu sampel yang dipilih berdasarkan kuota yang telah ditentukan oleh peneliti. Penelitian ini melibatkan 440 mahasiswa, peneliti memberikan kuota sebanyak 50 mahasiswa, di tiap universitasnya.

Adapun yang menjadi variabel dalam penelitian ini (1)Variabel bebas : role model yaitu persepsi subjek terhadap figure dalam perilaku antikorupsi. Figure tersebut diantaranya orang tua, guru/dosen, temandan tokoh masyarakat. (2)Variabel moderator : Religiusitas merupakan keyakinan beragama islam yang dipraktikan dalam perbuatan, melakukan yang diperintah dan mengindari yang dilakukan serta mengakui persaudaraan antar umat muslim.(3) Variabel terikat : antikorupsi adalah rencana, hasrat dan keyakinan untuk cenderung menghindari perilaku jahat, busuk, dan merusak yang berkaitan dengan penyelewengan kekuasaan. Aspek antikorupsi meliputi anti bribe, anti gratification, anti fraud, anti mark up, anti black mail dan anti nepotism.

Untuk mengukur tiga hal tersebut digunakan beberapa alat ukur, Psychological Measure of Islamic Religiousness (PMIR) Raiya (2008) yang telah diadaptasi sebelumnya oleh Namira (2015) kemudian diadaptasi kembali oleh peneliti. Sedangkan, variabel role model dan antikorupsi, diukur oleh skala yang telah dibuat peneliti yaitu Skala Role model (SRM) dan Skala Antikorupsi Mahasiswa Organisatoris (SAMO). Berikut hasil uji validitas dan reliabilitas ketiga alat ukur tersebut.

Tabel 3. Hasil Uji validitas dan Reliabilitas Alat Ukur

\begin{tabular}{cccc}
\hline $\begin{array}{c}\text { Alat } \\
\text { Ukur }\end{array}$ & $\begin{array}{c}\text { Jumlah } \\
\text { Item } \\
\text { Valid }\end{array}$ & $\begin{array}{c}\text { Rentang } \\
\text { Indeks } \\
\text { Validitas }\end{array}$ & $\begin{array}{c}\text { Indeks } \\
\text { Reliabilitas }\end{array}$ \\
\hline PMIR & 23 item & $\begin{array}{c}0,173- \\
0,596\end{array}$ & 0,814 \\
& & $0,170-$ & \\
& & 0,857 \\
SRM & 33 item & 0,594 & \\
& & & \\
SAMO & 24 item & $0,305-$ & 0,875 \\
& & 0,629 & \\
& & & \\
\hline
\end{tabular}

Penelitian ini dimulai dengan mempersiapkan instrumen (skala). Selanjutnya dilakukan try out pertama dilakukan pada 60 subjek mahasiswa di Universitas Muhammadiyah Malang, SAMO berhasil mencapai nilai validitas dan reliabilitas yang sesuai, dan dapat langsung digunakan. Namun, pada PMIR dan SRM, belum mencapai nilai tersebut. Selanjutnya, peneliti melakukan try out kedua hingga instrumen penelitian mencapai angka validitas dan reliabilitas yang sesuai. Proses pengambilan data di sembilan universitas sample di Jawa Timur.

Data perlu melewati uji prasyarat sebelum dilakukan analisa data menggunakan Moderated Regression Analysis (MRA). Uji prasyarat tersebut yaitu, uji normalitas, uji multikolinearitas, uji heteroskedastisitas, dan uji autokorelasi. Berikut tabel hasil analisanya MRA : 
Tabel 4. Hasil Analisa MRA (F.Hayyes)

\begin{tabular}{|c|c|c|c|c|c|c|}
\hline \multicolumn{7}{|l|}{ Model } \\
\hline & coeff & se & $t$ & $\mathrm{p}$ & LLCI & ULCI \\
\hline constant & 64,2032 &, 4536 & 141,5382 &, 0000 & 63,3117 & 65,0947 \\
\hline REL &, 0651 &, 0456 & 1,4281 & , 1540 &,- 0245 &, 1547 \\
\hline RM &, 2060 &, 0286 & 7,2107 &, 0000 & 1498 & , 2621 \\
\hline int 1 &, 0021 &, 0026 &, 8098 &, 4185 &,- 0030 &, 0071 \\
\hline
\end{tabular}

Hasil analisa data, menunjukkan data tidak signifikan $(p=0.4185 ; p>0.05)$. Analisa regresi sederhana role model dan perilaku antikorupsi hasilnya $\operatorname{signifikan}(\mathrm{p}=0,0 ; \quad \mathrm{p}<0.05)$. Variabel religiusitas tidak sesuai menjadi variabel moderator, pada pengaruh role model terhadap perilaku antikorupsi. Sehingga, tingkat religiusitas yang dimiliki individu tidak mampu meningkatkan maupun mereduksi pengaruh role model terhadap perilaku antikorupsi. Seseorang yang memiliki role model antikorupsi yang kuat, tinggi rendahnya tingkat religiusitas tidak memberikan pengaruh munculnya perilaku antikorupsi.

Tabel 5. Hasil Analisa Regresi Berganda

\begin{tabular}{|rrrrrrr|}
\hline Model surmary & & & & & & \\
$R$ & $R-3 q$ & L.SE & $\mathbb{E}$ & df1 & df2 & $p$ \\
3625 & 1,1314 & 88,7493 & 19,7880 & 3,0000 & 436,0000 &, 0000 \\
& & & & & & \\
\hline
\end{tabular}

Namun, dengan model analisa regresi berganda, religiusitas dan role model yang dimasukkan secara bersama dan kedudukannya sama sebagai variabel bebas, hasilnya $\operatorname{signifikan}(p=0,0 ; p<0.05)$, dengan $r$ square 0,1314 . Analisa regresi linier sederhana menunjukkan variabel religiusitas tidak memiliki pengaruh yang signifikan jika dihubungkan langsung dengan perilaku antikorupsi $(p=0,1540 ; p>0.05)$, hal ini yang membuat variabel religiusitas tidak dapat menjadi variabel moderat. Sedangkan, variabel role model jika dihubungkan langsung dengan perilaku antikorupsi hasilnya signifikan $(\mathrm{p}=0,0 ; \mathrm{p}>0.05)$. Dari hasil uji tersebut, dinyatakan bahwa hipotesa ditolak, variabel religiusitas tidak dapat menjadi variabel moderator, namun terdapat hubungan yang signifikan antara role model dan perilaku antikorupsi. Selanjutnya, dilakukan uji linieritas dari empat figure role model terhadap perilaku antikorupsi. Berikut tabel hasil uji linieritasnya :

Tabel 6. Hasil Uji Linieritas Empat Figure

\begin{tabular}{lcc}
\hline Figure & R Square & Persentase \\
\hline Guru/Dosen & 0,127 & $12,7 \%$ \\
Teman & 0,094 & $9,4 \%$ \\
Orang Tua & 0,087 & $8,7 \%$ \\
Tokoh & 0,070 & $7 \%$ \\
Masy. & & \\
\hline
\end{tabular}

Hasilnya, figure guru/dosen menempati persentase tertinggi $(12,7 \%)$ yang mempengaruhi perilaku antikorupsi. Hal ini berarti lembaga pendidikan memiliki peran yang kuat dalam penanaman perilaku antikorupsi pada individu. Selanjutnya, teman sebaya menempati posisi tertinggi kedua $(9,4 \%)$ yang memiliki pengaruh terhadap perilaku antikorupsi.

Tabel 7. Tingkat Persepsi Perilaku Antikorupsi terhadap Figure Role Model

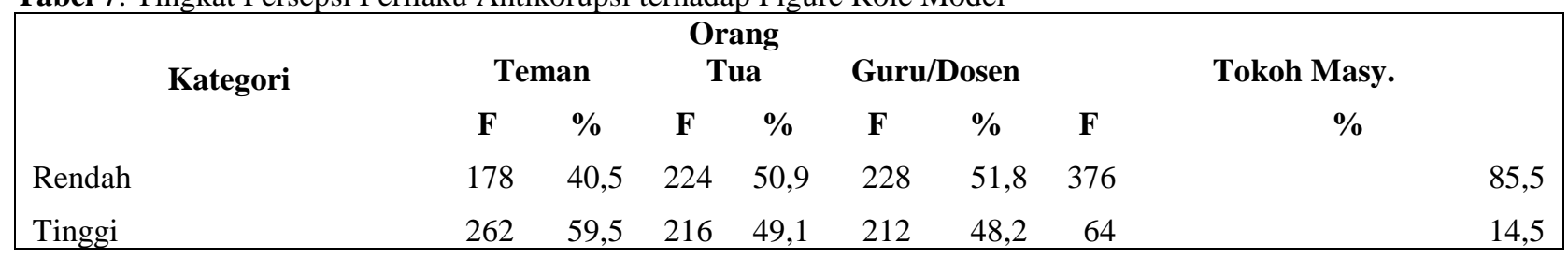


Tabel 8. Kategorisasi Ketiga Variabel

\begin{tabular}{|c|c|c|c|c|c|c|c|c|c|}
\hline \multirow{2}{*}{ Kategori } & \multicolumn{3}{|c|}{ Role model } & \multicolumn{3}{c|}{ Religiusitas } & \multicolumn{3}{c|}{ Antikorupsi } \\
\cline { 2 - 11 } & Interval & F & \% & Interval & F & \% & Interval & F & \% \\
\hline Rendah & $45-85$ & 229 & 52,0 & $48-82,5$ & 126 & 28,6 & $27-61,5$ & 169 & 38,4 \\
\hline Tinggi & $84-125$ & 211 & 48,0 & $82,6-117$ & 314 & 71,4 & $61,6-96$ & 271 & 61,6 \\
\hline
\end{tabular}

Namun, figure guru/dosen ini justru dipersepsikan subjek memiliki perilaku antikorupsi yang rendah $(51,8 \%)$. Hal ini berarti, figure guru/dosen masih dianggap memberikan contoh perilaku antikorupsi kepada peserta didiknya.

Selain itu, berdasarkan skor total tiap variabelnya, sebagian subjek memiliki perilaku antikorupsi yang rendah $(38,4 \%)$ sehingga cenderung melakukan perilaku korupsi.

Hasil dari penelitian membuktikan bahwa variabel religiusitas tidak dapat menjadi variabel moderator. Sejalan dengan hal tersebut, penelitian yang dilakukan oleh Lau,Choe dan Tan (2013) yang menggunakan variabel religiusitas ekstrinsik sebagai variabel moderator antara money ethics (etika uang) dan tax evasion (penghindaran pajak) juga menyatakan bahwa variabel religiusitas ekstrinsik tidak dapat menjadi variabel moderator. Pada penelitian tersebut religiusitas dibagi menjadi ekstrinsik dan instrinsik. Variabel intrinsiknya berhasil menjadi variabel moderator. Sehingga, variabel religiusitas tidak secara mutlak dapat menjadi variabel moderator dalam berbagai penelitian, karena hasil beberapa penelitian yang berbeda.

Salah satu penyebabnya, karena diketahui bahwa religiusitas tidak memiliki pengaruh yang signifikan jika dihubungkan langsung dengan perilaku antikorupsi. Hal ini yang mengganggu variabel role model dan perilaku antikorupsi. Rashid dan Ibrahim (2008) juga menyebutkan bahwa, religiusitas yang tinggi bukan jaminan bahwa individu tersebut juga memiliki ethical value yang tinggi juga. Sehingga, terkait pengaruh variabel religiusitas pada berbagai penelitian korupsi maupun unethical behavior lainnya masih tidak konsisten dan terdapat gap.

Selain itu religiusitas yang merupakan hal normatif, dalam proses pengukuran dapat menimbulkan subjek menjawab sesuai norma yang ada, sehingga tidak menampakan perilaku religiusitas yang sesungguhnya dimiliki. Variabel 
praktik risywah sebagaimana melarang pengambilan harta yang bukan haknya secara batil. (QS. Al-Baqarah:188). Sehingga pemaknaan secara mendalam terkait religiusitas perlu dimiliki oleh diri individu tersebut.

Guru/dosen memiliki pengaruh yang positif terhadap perilaku antikorupsi. Dalam penelitian ini ditemukan guru/dosen memiliki sumbangan $12 \%$ terhadap munculnya perilaku antikorupsi. Guru/dosen merupakan figure yang ada di dalam lingkungan pendidikan, diamana mengajarkan nilai moral baik dalam bentuk kurikulum maupun materi bahasan di sekolah dan kampus, yang menggunakan beberapa pendekatan mulai dari pembentukan kebiasaan, pembelajaran materi hingga modelling (Nurdin, 2014).

Berdasarkan hasil penelitian ini, pembentukan perilaku antikorupsi yang efektif, tidak hanya dilakukan lewat pengajaran dan penanaman nilai-nilai moral yang tepat pada individu. Namun, juga perlu adanya figure antikorupsi, yang ada di sekitar mahasiswa. Figure inilah yang akan memberikan contoh dan suri tauladan perilaku antikorupsi. Figure yang ada di sekitar kehidupan mahasiswa ini menurut Fiest (2010) merupakan representasi dari model atraktif yang membuat individu cenderung melakukan modelling terhadap segala perilaku yang dilakukan oleh model/figure tersebut.

\section{SIMPULAN}

Berdasarkan hasil penelitian yang telah dipaparkan sebelumnya, dapat disimpulkan bahwa role model memiliki hubungan positif terhadap perilaku antikorupsi, dengan sumbangan sebesar $12,7 \%$. Namun, dalam Moderated Regression Analysis (MRA) diketahui bahwa variabel religiusitas bukan merupakan variabel moderator yang dapat mempengaruhi kuat atau lemahnya pengaruh antara role model dan perilaku antikorupsi. Salah satu penyebabnya, karena religiusitas tidak signifikan jika dihubungkan secara langsung dengan variabel perilaku antikorupsi. Sehingga, tinggi rendahnya religiusitas seseorang jika ia tidak memiliki figure antikorupsi, maka ia akan berperilaku korupsi, Selain itu, dari keempat figure yang ada pada variabel role model diketahui bahwa kesemuanya berpengaruh signifikan, khususnya guru/dosen yang memiliki sumbangan prediktor terbesar, yaitu $12,7 \%$ terhadap munculnya perilaku antikorupsi pada mahasiswa organisatoris. Dapat disimpulkan bahwa role model merupakan variabel yang secara independen mempengaruhi perilaku antikorupsi.

\section{SARAN}

Hasil penelitian ini dapat menjadi masukan agar mahasiswa menemukan figure yang tepat dalam membentuk perilaku antikorupsi. Guru/dosen yang memiliki peran kuat, perlu memberikan contoh perilaku dan pendidikan antikorupsi, terutama di lingkungan pendidikan. Sehingga dapat menjadi acuan bagi pemerintah dalam menentukan kebijakan terkait pendidikan antikorupsi. Perlu peningkatan pengetahuan guru/dosen tentang perilaku antikorupsi, yang menjadi figure bagi peserta didiknya guna mencegah perilaku antikorupsi sejak dini. Bentuk tindak lanjut penelitian ini, perlu adanya teknik intervensi melalui psikoedukasi kepada guru/dosen serta mahasiswa, terkait perilaku antikorupsi hingga adanya pemaknaan secara mendalam dalam kesehariannya. Pemahaman yang baik secara kognitif terkait contoh perilaku korupsi, membuat individu dapat menghindari perilaku korupsi tersebut, sehingga terwujud perilaku antikorupsi. Selanjutnya, untuk peneliti yang juga akan mengambil topik sejenis, disarankan untuk menggunakan alat ukur yang itemnya secara langsung mengaplikasikan perilaku antikorupsi. Selain itu, peneliti menyarankan agar peneliti selanjutnya menggunakan variabel-variabel lain yang mempengaruhi perilaku antikorupsi sehingga akan semakin memperkaya bahan kajian dalam psikologi sosial terutama di bidang kajian korupsi.

\section{Daftar Pustaka}

Aultman,M.G. (1976). A social psychological approach to the study of police corruption. Journal of Criminal Justice Volume 4.

Bandura, A. (1986). Social foundation of thought and action: A social cognitive theory. Englewood Cliffs, NJ: Prentice Hall.

Boeree, G. (2010). Personality theories: melacak kepribadian anda bersama psikolog dunia. Jogjakarta : Primasophie. 
Budiharto, S. (Februari, 2015). Peran kepemimpinan profetik dalam kepemimpinan nasional. Presented in at the 1st National Conference on Islamic Psychology (NCIP), Yogyakarta.

Dayakisni, T. (2015). Hubungan sinisme sosial dengan sikap remaja terhadap korupsi. Seminar Psikologi dan Kemanusiaan, Psychology Forum, UMM.

Desmita. (2005). Psikologi perkembangan. Bandung : Remaja Rosdakarya.

Falah, F. (2012). Perilaku korup di mata mahasiswa, Prosiding Seminar Nasional Psikologi Islami, 151-158.

Feist, J.\& Feist, G.J. (2010). Teori kepribadian. Jakarta : Salemba Humanika.

Gachter,S.,\& Renner,E. (2014). Leaders as role models for the voluntary provision of public goods. CeDEx Discussion Paper No. 2014-11 University of Nottingham.

Gathy, R., Patternostro, S., \& Rigolini, J. (2003). Individual attitude toward corruption ? Do social effect matters. World Bank Policy Research Working Paper 3122, August 2003.

Hidayat, K. (2010). Psikologi korupsi. From: www.antikorupsi.org/en/content/psikologi-

korupsi .

Lau,T.C., Choe,K.L., \& Tan,L.P. (2013). The moderating effect of religiosity in the Relationship between money ethics and tax evasion. Asian Social Science; Vol. 9.

Nurdin,H.M. (2014). Pendidikan antikorupsi: strategi internalisasi nilai-nilai islami dalam Menumbuhkan kesadaran antikorupsi di sekolah. Yogyakarta : Ar-ruzz Media.

Paloutzian,R.F., \& Park,C.L. (2003). Handbook of the psychology of religion and spirituality. New York : The Guilford Press.

Raiya,H.A. (2008). A psychological measure of islamic religiousness: evidence for relevance, reliability and validity. Disertasi doktoral, Bowling Green State University,USA

Rashid,M.Z. \& Ibrahim,S. (2008). The Effect of Culture and Religiosity on Business ethics: A Cross-cultural Comparison. Journal of Business Ethics, 82.

Reber, A.S. dan Reber, E.S. (2010). Kamus psikologi. Yogyakarta : Pustaka Pelajar
Rubiyantoro, Y. (2014). Kembangkan karakter sejak usia dini. DIKBUD No. 03 Tahun V. From : http://www.kemdiknas.go.id/ .

Thabarsi,A.H. (1385 H) Misykât al-Anwâr. Kitabkhane Haidariyyah. Najaf. from : islamquest.net .

Transparency International Indonesia. (2015). Indeks persepsi korupsi di Indonesia. Harian Kompas, 11 Desember 2015.

Wahyuni, Z. I., Adriani, Y., dan Nihayah, Z. (2015). The relationship between religious orientation, moral integrity, personality, organizational climate and anti corruption intentions in Indonesia. International Journal of Social Science and Humanity, Vol. 5, No. 10.

Wakhidah, N. (2014, April). Revitalisasi peran keluarga dalam pendidikan antikorupsi menuju 100 tahun kemerdekaan Indonesia, from : http://psikologi.uin-malang.ac.id.

Walida, H.A.. (2015). Hubungan religiusitas dengan sikap terhadap korupsi pada mahasiswa.Skripsi, Fakultas Psikologi Universitas Muhammadiyah Malang. 